\title{
Project-Based Learning Approach for Teaching Mobile Application Development Using Visualization Technology
}

\author{
https://doi.org/10.3991/ijet.v15i08.12335 \\ Zhanat Nurbekova \\ L.N. Gumilyov Eurasian National University, Nur-Sultan, Kazakhstan \\ Vadim Grinshkun \\ Moscow City University, Moscow, Russian Federation \\ Gaukhar Aimicheva ( $\left.{ }^{凶}\right)$, Bakyt Nurbekov \\ L.N. Gumilyov Eurasian National University, Nur-Sultan, Kazakhstan \\ aimicheva@mail.ru \\ Kalima Tuenbaeva \\ Al-Farabi Kazakh National University, Almaty, Kazakhstan
}

\begin{abstract}
This article is devoted to the experience of applying the Blended Project-Based Learning Approach Using Visualization Technology in teaching mobile application development for IT-students. This technology is based on a project-based method, pair programming, teamwork and using of digital educational resources as a visual learning content. The authors describe the impact of the used teaching methods and digital educational resources on the student's cognitive skills during the mobile application development in the workshop where the students gained hands-on experience on mobile application development through «active doing» method, interactive tasks and creating different types of mobile application projects. The workshop's curriculum is developed in terms of the scaffolding. So, the students improve the skills develop projects starting from simple «Hi, Kazakhstan!» to a complete software with the functions of search and update from the Internet. The well-designed project topics on development mobile application arise the interest and provide the high motivation of the learners.

The impact of Blended Project-Based Learning Approach is evaluated through the questionnaire, testing and evaluation of mobile application projects developed by students. The effectiveness of such an approach for teaching mobile application development is confirmed by the empirical data.
\end{abstract}

Keywords-Mobile application development, project-based learning approach, digital educational resources, cognitive skills, pair programming, interactive tasks 


\section{Introduction}

Mobile computing is one of the rapidly developing areas of computing. Mobile applications are successfully used as part of innovative educational technologies to enhance learning in various disciplines [1], [2] and the demand for competent mobile application developers globally is high [3]. But the issue of teaching mobile application development is relevant to this day [4-13], [15], [18], [19], [21-33].

After the ACM computing curricula was published in 2013, where many of the courses covered the topic of mobile computing, the mobile application development course began to be implemented by many universities. A feature of the mobile application development course is in the interdisciplinary correlations between traditional areas of computer science such as software development, human-computer interaction, web programming, data security, and network interaction. In view of this feature the earlier works considered the issues of integrating the mobile application development course into the «Computer Science» curricula [4], [9], [11], [12]. So teaching mobile application development can be implemented:

- As a separate topic in the introductory programming courses

- In the basic courses, such as «Algorithms and data structures», «Database systems», «Operating systems»

- In the elective courses «Software Development», «Human - computer interaction» at senior courses

- As the projects on courses connected with the network programming, the distributed computing systems on senior courses

- As capstone project and a final year project

According to [14], [15], [17], [23-25] the content of mobile application development courses are based on the basic concepts of mobile software such as: 1) user interface design and usability; 2) device cooperation, 3) hardware issues; 4) data handling; 5) application interaction; 6) programming issues.

As research and MOOC-courses analysis has shown the main goals of teaching mobile application development, which can be formed as: 1) learning the computer science principles in terms of mobile computing; 2) the computational, logical, design thinking skills development; 3) the mobile application user interface design skills development; 4) development the skills of mobile application analysis, design, implementation and testing [4-13], [15], [18-19], [21-27], [29-30].

The issues of the teaching mobile application development with the emphasis to cognitive difficulties of understanding, remembering, applying, analyzing and creating during mobile application programming are not adequately investigated [22], [24], [28], [30], [32-33].

The scientific research about applying the set of approaches to teaching mobile application development for iOS is considered in the work [22] and provides the evidence that the students haven't been encouraged with the problem-based approach to learn course content. Students wish to know a problem-solving algorithm, as it is, and do not wish to know how to obtain such an algorithm. It is evident that the 
students are only able to understand, to remember and to apply the gained knowledge. At the same time, the authors note that students have the cognitive difficulties of acquisition the topics as «Optionals», «Closures» and «Properties», where the analysis and creating skills are required. To increase the achievement, especially on complex topics, the authors improved the learning content by decomposing the main learning goal into sub goals that are revealed during the 1-2 minute learning video modules. Thus, the authors have been able to increase the students' attention concentration and achieve complex topics, which require analysis and creating skills, to $80 \%$.

As it is known, to acquire the mobile application development better it is necessary to focus on the development of skills which are implied in the knowledge and application of object-oriented programming concepts (abstraction, encapsulation, inheritance, polymorphism) and design patterns in mobile application development [24], [30], [32]. And the most students' cognitive difficulties on programming mobile applications arise in this field [24]. For this reason the authors suggest an innovative teaching methodology using hands-on mobile programming techniques, specific projects and the «active doing» method for teaching cross-platform two-dimensional mobile game development. The «active doing» method provides students to gain hands-on experience by implementing the theoretical knowledge on mobile application development in practice.

In [30], the authors teach to apply the object-oriented programming skills in practice for mobile game development. The authors suggest the training modules on mobile game development which includes the hands-on projects and guidelines for teaching the computer science students in junior courses. The hands-on projects demonstrate how to develop mobile games, thereby motivate students to learn the content and the object-oriented programming fundamental principles.

Interactive tasks to train programming in real time [33] are being used to teach the skills and concepts of the mobile application programming course as The Mobile Computing with App Inventor - CS Principles» on edX platform. The platform provides an assessment the task performance and in case of errors, teaches to write a code correctly. In response to such interactive tasks, the students are acquired skills for the understanding, remembering, applying and analyzing on mobile application development.

In teaching mobile application development, it is necessary to consider that students acquire programing skills better programming in a pair or in a team through collaborative learning [34], [35]. Besides, there are empirical data which have been proved that IT-students prefer the visual and kinesthetic learning style [36]. Many researches have been experimentally proved the effectiveness of a project-based approach to teach mobile application development for developing the design thinking and such soft-skills as critical thinking, problem solving, teamwork and communication skills [24], [29], [30], [40].

The conducted overview of researches lead to make a conclusion about the necessity of applying the project-based learning approach, pair programming, using interactive tasks in real time, watching video instructions, and using «active doing» method for better development of cognitive skills on mobile application development. 
The following research questions will be addressed in this study: «To what cognitive skills are the discussed above learning methods impacted?», «To what extent the mentioned above methods impact to the learning efficiency and to the students' motivation learn a mobile development course?», «How does applying visualization technology enhance learning process?».

The considered methods were implemented during a workshop on the mobile application development using the digital educational resources (DER) as a visualization technology. The research results and applied methods are discussed below in the relevant sections.

\section{Materials and Methods}

The first and second year students of the specialties like «Computer science», «Software and computer engineering», «Information systems» took part in the workshop which was held within two weeks with the volume of 60 hours. During the workshop 89 students acquired skills on the mobile application development for iOS on the integrated development environment Xcode using the object-oriented programming language Swift. Such a programming language combines the principles of object-oriented and functional approaches of programming. The core concepts are «object» and «class», while the main logical methods used in the mobile application development are abstraction, analysis, synthesis, induction, deduction, generalization and classification. Correct implementation of the logical methods provide the developing a clear hierarchy of classes, data structure and mobile application logic that affects the mobile application efficiency.

During the workshop, the teaching process was based on visual and kinesthetic learning style, implemented by using the DER and project-based method. The visualized educational content of the workshop was presented by DER covered all fifteen course topics.

The structure of each DER includes the following units:

1) The theoretical unit is a multimedia and animation unit which represents learning content on mobile application development as a diagrams, tables, charts, images, animation, video and audio fragments.

2) The training unit represented by interactive tasks-simulators, which allows students to increase their mental activity in mobile application development, reinforce skills, and create a «success feedback» in students's minds and increase their motivation to further study of the course content through the training function (see Figure 1).

3) The control unit is represented by test tasks with a single or multiple choices with the correct answers. After testing is complete, the test results have been shown at the screen. The students can get to know the correct answers and compare them with their own answers. This part of work allows to make the self-analysis and promotes self-development of the student's personality. 

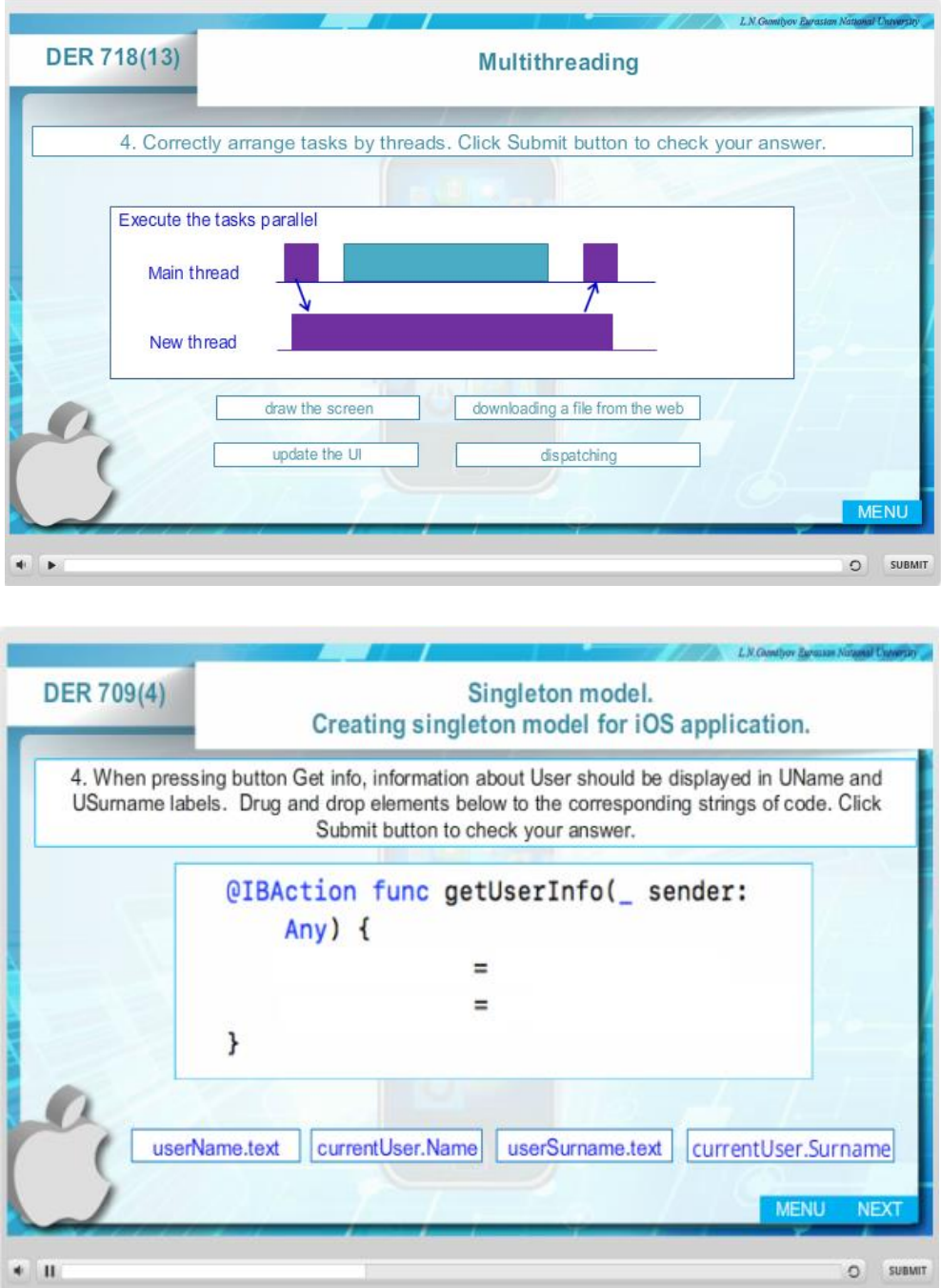

Fig. 1. Examples of the interactive tasks

DER are developed in accordance with the spiral approach [37-39] which proposes scaffolding and repeating content at increasingly complex levels. In addition, each DER includes the video-clips demonstrating mobile application development step-bystep from simple «Hi, Kazakhstan!» to a complete software with functions of search and update from the Internet.

The lesson structure is not a linear, but of a spiral structure. It means that the challenge set at the beginning of the lesson requires to be returned to it repeatedly during the lesson. That moment, students were suggested to perform the following types of learning activities: 
1. Learn the course content with the DER;

2. Perform the interactive tasks;

3. Perform the lab sessions based on pair programming;

4. Control assessment.

At the end of the lesson, the students had time for a team work on the educational project.

To ensure the effective teaching of the mobile application development we should assess the impact of the used teaching methods and techniques on the cognitive skills development, according to Bloom's taxonomy. Table 1 presents data about the assessment of the DER impact on the cognitive skills classified according to Bloom's taxonomy and students' achievement through mobile application development.

Table 1. The impact of the DER on the cognitive skills, classified according to Bloom's taxonomy and developing through mobile application development

\begin{tabular}{|c|l|l|}
\hline № & \multicolumn{1}{|c|}{ The unit of the DER } & \multicolumn{1}{|c|}{ The cognitive skills } \\
\hline 1 & The multimedia and animation unit & remember, understand \\
\hline 2 & The training unit with the interactive tasks-simulators & remember, understand, apply, analyze \\
\hline 3 & The control unit & remember, understand, analyze, evaluate \\
\hline 4 & $\begin{array}{l}\text { The video-clips demonstrating mobile application } \\
\text { development }\end{array}$ & remember, understand, apply, analyze \\
\hline
\end{tabular}

As it is showed in the table, DER provides the asquisition only as a part of the cognitive skills, mostly «remember», «understand» and «apply». To ensure the asquision of other most important cognitive skills of analysis, evaluation and creating, students were offered other learning activities using the methods discussed in the introductory part of the article (see Table 2).

Table 2. The impact of teaching methods on the cognitive skills during the mobile application development

\begin{tabular}{|c|l|l|}
\hline № & \multicolumn{1}{|c|}{ The teaching methods } & \multicolumn{1}{|c|}{ The cognitive skills } \\
\hline 1 & $\begin{array}{l}\text { Performing the lab sessions based on pair } \\
\text { programming }\end{array}$ & $\begin{array}{l}\text { remember, understand, apply, analyze and } \\
\text { evaluate }\end{array}$ \\
\hline 2 & $\begin{array}{l}\text { The «active doing» method for work on the self- } \\
\text { study and educational projects. }\end{array}$ & $\begin{array}{l}\text { remember, understand, apply, analyze, evaluate } \\
\text { and create }\end{array}$ \\
\hline 3 & $\begin{array}{l}\text { Team work on educational projects for the } \\
\text { development of mobile applications. }\end{array}$ & $\begin{array}{l}\text { remember, understand, apply, analyze, evaluate } \\
\text { and create }\end{array}$ \\
\hline
\end{tabular}

To assess the impact of used approach on the students' cognitive skills development the survey, control testing, evaluation of interactive tasks, individual work, criterial assessment of educational projects for mobile applications were applied.

The course curriculum is offered to the students the next topics of mobile application projects to perform them during hands-on and self-study work: 
Paper-Project-Based Learning Approach for Teaching Mobile Application Development Using ...

\begin{tabular}{|c|l|l|}
\hline № & \multicolumn{1}{|c|}{ Hands-on projects for lab sessions } & \multicolumn{1}{c|}{ Projects for self-study work } \\
\hline 1 & «Hi, Kazakhstan!», «Weather forecast». & Student Portfolio. \\
\hline 2 & Calculator. & Game «777». \\
\hline 3 & «Guide of the Kazakhstan's City». & «7 Wonders of the World». \\
\hline 4 & $\begin{array}{l}\text { «The major tourist attractions of Astana with } \\
\text { positioning on the map». }\end{array}$ & «Map of sports complexes in Astana». \\
\hline 5 & «Work with a student database using Json». & «Astana business-directory». \\
\hline 6 & «Threading». & «Currency Converter». \\
\hline 7 & «App for students testing assessment». & Game App «Who Wants to Be a Millionaire?». \\
\hline
\end{tabular}

The instructional video, interactive tasks-simulators, hands-on and the self-study projects encourage students to acquire the cognitive skills required at all stages of mobile application development: analyzing and formalization of a problem, designing the app architecture and logic, codding, testing, debugging and evaluating of the mobile application. In addition, students gain experience in using logical methods for mobile application development (abstraction, analysis and synthesis, induction and deduction, generalization and classification) to designing a hierarchy of classes and objects, defining protocols and other class properties, using blocks to optimize code, access to remote database and process threading in order to save mobile device resources and to develop an optimized mobile application.

\section{Results and Discussion}

As experiment showed that using the DER as visualization technology for explaining educational material allows teachers to save the time. Instead of 50 minutes duration of the lecture within the traditional approach, using the DER reduces the actual time to 10-12 minutes. The possibility to perform an interactive task repeatedly provides consolidation of knowledge and developing hands-on skills on topics such as designing of an architecture, using components, defining outlets, class properties, coding, thereby developing necessary cognitive skills. In addition, the DER can be implemented both in LMS and interactive platforms, for example, Google Classroom, for implementing personalized learning technology [41], [42].

One of the benefits of using the DER is to increase the motivation of students in comparison with the traditional teaching. The survey has been examined the students motivation to study the mobile application development course using the DER. 94.4\% of students have found the mobile application development course interesting and the using DER for learning the course content efficient. Due to the post-intervention survey of students aimed to evaluate DER, it was revealed that the most useful block of DER is the video-clips of the hands-on mobile application development and the possibility of self-study complex topics (see Figure 2). 


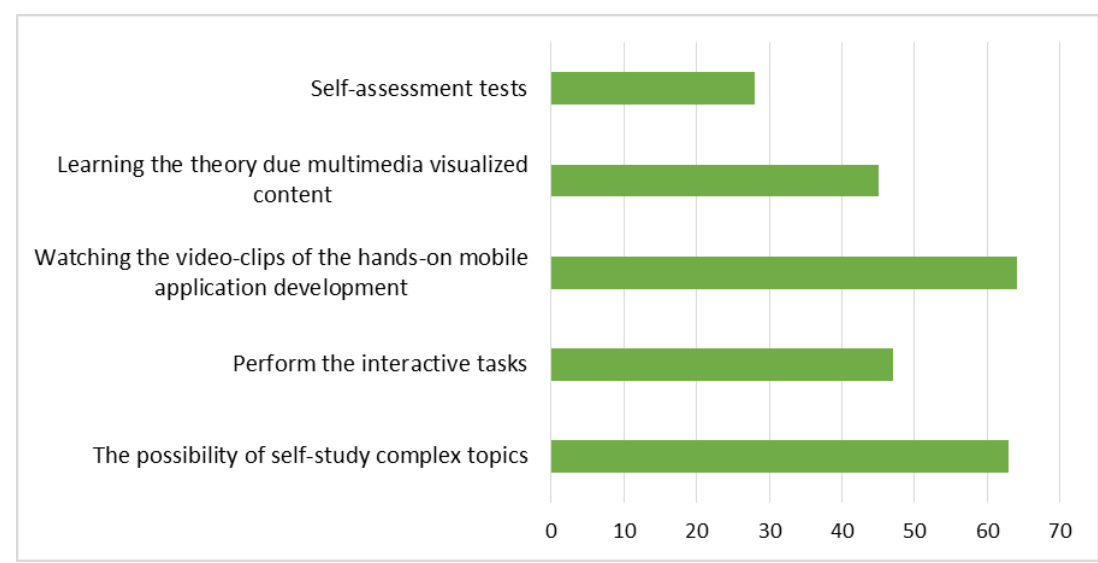

Fig. 2. The post-intervention survey of students aimed to evaluation DER

Figure 3 shows the project types and degree of their completeness by students. According to the survey results (see figure 3), the tasks for self-study work on mobile application development turned out to be the most difficult for implementation. It is obvious that students have not sufficient skills on «analysis» and «creating» for the mobile application development. During the classes students in collaboration with the teacher analyzed the mistakes in projects performance within self-study work, which has been positively impacted on the team projects performance at the level of $92 \%$.

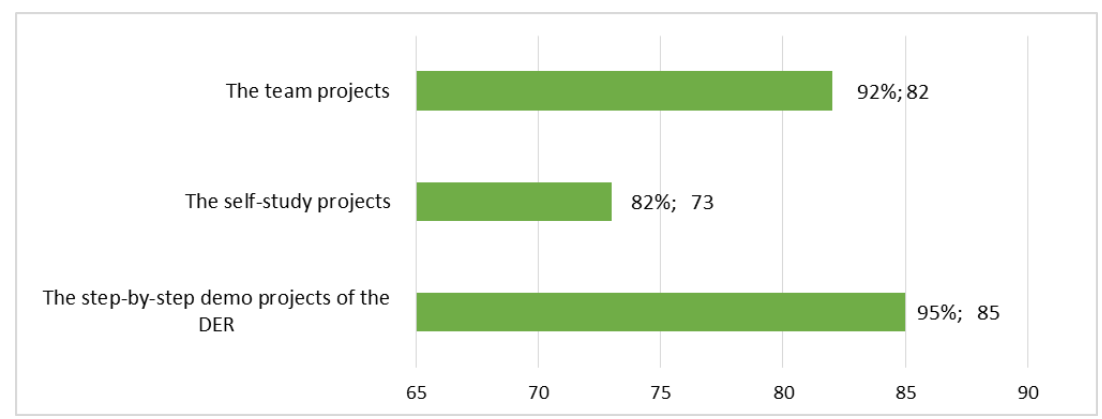

Fig. 3. The project types and degree of their completeness

At a result of the workshop students developed team projects on different topics such as Directory of universities of Kazakhstan, Recipe mobile-book, Kazakh-English dictionary, Math interactive simulator for preschool age children, Logic puzzle game, etc. The developed mobile application projects had been evaluated by three levels (low, sufficient and high) using the criterial assessment. Due to the criterial assessment system the qualitative data were collected which allowed to appraise the following knowledge and skills of students to develop mobile applications:

- The skill to formalize the requirements and define the data structure of the mobile application; 
- The skill to identify the abstract levels within the Model-View-Controller model, the classes and objects;

- The skill to determine the mobile application states and the sequence of segues between mobile application views;

- The knowledge and skill to determine the optimal data structure and data access methods;

- The knowledge and skill to use components;

- The skill to code class algorithms using patterns, closures and other programming language mechanisms;

- The skill to debug the application code;

- The skill to evaluate the mobile application conformity to initial specification requirements.

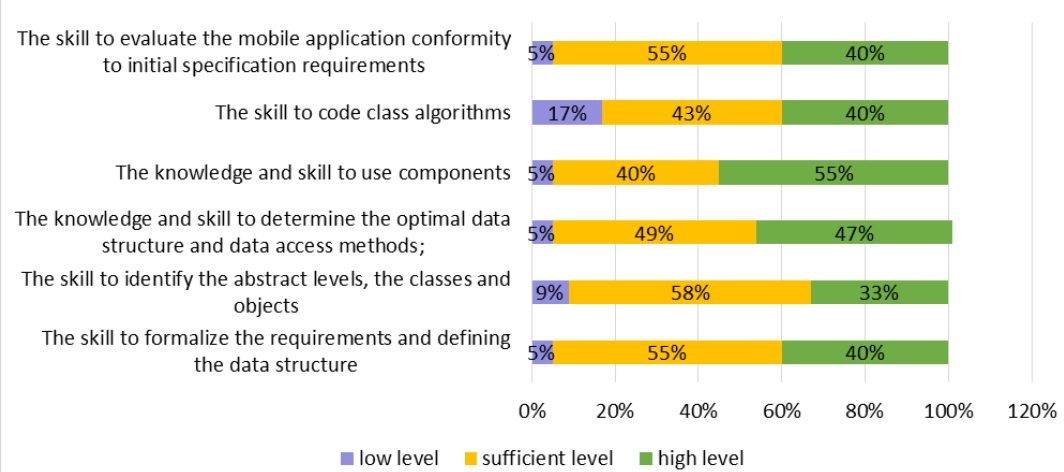

$\begin{array}{lllllll}0 \% & 20 \% & 40 \% & 60 \% & 80 \% & 100 \% & 120 \%\end{array}$

घlow level $\quad$ sufficient level $\quad$ nigh level

Fig. 4. The results of assessment of the students' knowledge and skills to develop mobile applications

The results of evaluating students' projects represented on the histogram (see figure 4) show that some students have a low level of knowledge and skills in: «Formalizing the requirements and defining of the data structure of the mobile application», «Identification of the abstract levels, classes and objects», «Coding of class algorithms using patterns, closures and other programming language opportunities». This is due to the fact that to acquire these topics it is necessary to require cognitive skills of «analysis», «creating», «using of logical methods for mobile application development». And another reason why the students have such a low level of knowledge on the mentioned above topics may be an insufficient level of objectoriented programming knowledge which is a basic for mobile application development. The above assumption is proved by results of the preliminary survey that the most of students $(90 \%)$ learned the Pascal programming language as a basic one (see figure 5) and in the second half-year, students learned one of the objectoriented languages such as $\mathrm{C}++(73 \%)$, Java (47\%), Python $(26 \%)$. 


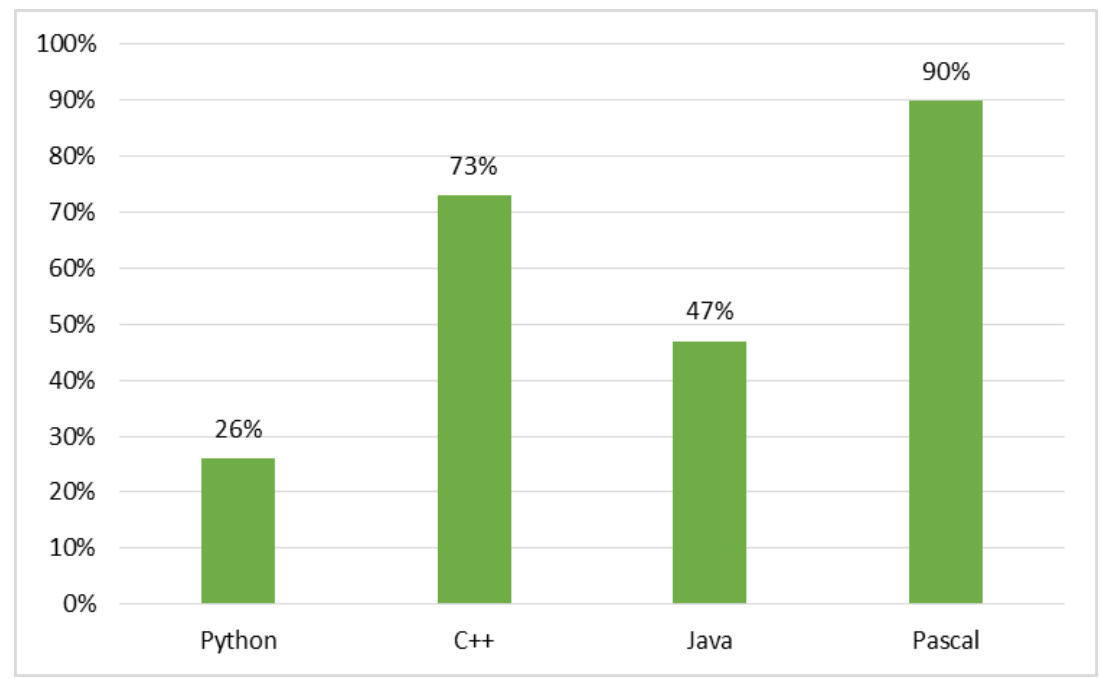

Fig. 5. The results of the survey on the programming languages knowledge

\section{Conclusion}

Thus, this research allowed to investigate the effectiveness of an blended approach based on project-based learning, pair and team programming, using DER for provide interaction and visualizing of learning content and implementation «active doing» during hands-on session as well as analysis of students' cognitive skills through the criterial assessment of developed projects. Furthermore, this work could provide a framework for an instructional design of a methodological system on teaching mobile application development aimed to feasible choice of the appropriate learning techniques and approaches.

\section{$5 \quad$ References}

[1] Dothang Truong. (2014). How to design a mobile application to enhance teaching and learning?. International Journal of Emerging Technologies in Learning (iJET). Vol 9, No 3. (pp. 4-11). https://doi.org/10.3991/ijet.v9i3.3507

[2] Shanshan Wang. (2017). Construction of mobile teaching platform for the ideological and political education course based on the multimedia technology. International Journal of Emerging Technologies in Learning (iJET). Vol 12, No 09. (pp. 156-167). https://doi.org/ 10.3991/ijet.v12i09.7496

[3] G. Aimicheva, Zh. Kopeyev, Zh. Ordabayeva, N. Tokzhigitova, S. Akimova. (November, 2019). A spiral model teaching mobile application development in terms of the continuity principle in school and university education. Education and Information Technologies. ISSN: 1360-2357. https://doi.org/10.1007/s10639-019-10051-z 
[4] Mahmoud, Q.H. (2008). Integrating mobile devices into the computer science curriculum. In 2008 38th Annual Frontiers in Education Conference (pp. S3E-17). IEEE. https://doi. org/10.1109/fie.2008.4720686

[5] Mahmoud, Q. H. and Dyer, A. 2007. Integrating BlackBerry wireless devices into computer programming and literacy courses. In Proceedings of the 45th Annual Southeast Regional Conference (Winston-Salem, NC, Mar. 23-24, 2007). ACM-SE 45. ACM, New York, NY, 495-500. https://doi.org/10.1145/1233341.1233430

[6] Scharff, C., Wasilewska, A., Wong, J., Bousso, M., Ndiaye, I., \& Sarr, C. (2009). «A model for teaching mobile application development for social changes: Implementation and lessons learned in Senegal». In 2009 International Multiconference on Computer Science and Information Technology (pp. 383-389). IEEE. https://doi.org/10.1109/imcsit. $\underline{2009.5352697}$

[7] Scharff, C., \& Verma, R. (2010). Scrum to support mobile application development projects in a just-in-time learning context. In Proceedings of the 2010 icse workshop on cooperative and human aspects of software engineering (pp. 25-31). ACM. https://doi.org/ $10.1145 / 1833310.1833315$

[8] Matos, V., \& Grasser, R. (2010). Building applications for the Android OS mobile platform: a primer and course materials. Journal of Computing Sciences in Colleges, 26(1), 23-29.

[9] Mahmoud, Q.H., \& Popowicz, P. (2010). A mobile application development approach to teaching introductory programming. In 2010 IEEE Frontiers in Education Conference (FIE) (pp. T4F-1). IEEE. https://doi.org/10.1109/fie.2010.5673608

[10] Lutes, K., \& Shanklin, T. (2012). So you want to teach an iPhone programming course?. The ASEE Computers in Education (CoED) Journal, 3(1), 59.

[11] Mahmoud, Q.H. (2011). Best practices in teaching mobile application development. In Proceedings of the 16th annual joint conference on Innovation and technology in computer science education (pp. 333-333). ACM. https://doi.org/10.1145/1999747.1999 $\underline{844}$

[12] Hu, W., \& Guo, H. (2012). Curriculum architecture construction of mobile application development. In 2012 International Symposium on Information Technologies in Medicine and Education (Vol. 1, pp. 43-47). IEEE. https://doi.org/10.1109/itime.2012.6291243

[13] Xu, C. (2013). Classroom flipping as the basis of a teaching model for the course Mobile Application Development. World Transactions on Engineering and Technology Education, $11(4), 537-540$.

[14] Gordon, A.J. (2013, July). Concepts for mobile programming. In Proceedings of the 18th ACM conference on Innovation and technology in computer science education (pp. 58-63). ACM. https://doi.org/10.1145/2462476.2462483

[15] Stuurman, S., van Gastel, B. E., \& Passier, H. J. (2014, November). The design of mobile apps: what and how to teach?. In Proceedings of the Computer Science Education Research Conference (pp. 93-100). ACM. https://doi.org/10.1145/2691352.2691360

[16] Sykes, E.R. (2014). New methods of mobile computing: From smartphones to smart education. TechTrends, 58(3), 26-37. https://doi.org/10.1007/s11528-014-0749-2

[17] Flora, H.K., Wang, X., \& Chande, S.V. (2014). An investigation into mobile application development processes: Challenges and best practices. International Journal of Modern Education and Computer Science, 6(6), 1. https://doi.org/10.5815/ijmecs.2014.06.01

[18] Santos, A.R., Sales, A., Fernandes, P., \& Nichols, M. (2015). Combining challenge-based learning and scrum framework for mobile application development. In Proceedings of the 2015 ACM Conference on Innovation and Technology in Computer Science Education (pp. 189-194). ACM. https://doi.org/10.1145/2729094.2742602 
[19] Francese, R., Gravino, C., Risi, M., Scanniello, G., \& Tortora, G. (2015). Using ProjectBased-Learning in a mobile application development course - An experience report. Journal of Visual Languages \& Computing, 31, 196-205. https://doi.org/10.1016/ j.jvlc.2015.10.019

[20] Delia, L., Galdamez, N., Thomas, P., Corbalan, L., \& Pesado, P. (2015). Multi-platform mobile application development analysis. In 2015 IEEE 9th International Conference on Research Challenges in Information Science (RCIS) (pp. 181-186). IEEE. https://doi.org/ $10.1109 /$ rcis.2015.7128878

[21] Khmelevsky, Y., \& Voytenko, V. (2016). A new paradigm for teaching mobile application development. In Proceedings of the 21st Western Canadian Conference on Computing Education (p. 8). ACM. https://doi.org/10.1145/2910925.2910937

[22] Aarabi, P., Norouzi, N., Wu, J., \& Spears, M. (2016). 7 surprising lessons learned from teaching iOS programming to 30, 000+ MOOC students. In 2016 IEEE Frontiers in Education Conference (FIE) (pp. 1-4). IEEE. https://doi.org/10.1109/fie.2016.7757448

[23] Esakia, A., \& McCrickard, D. S. (2016). An adaptable model for teaching mobile app development. In 2016 IEEE Frontiers in Education Conference (FIE) (pp. 1-9). IEEE. https://doi.org/10.1109/fie.2016.7757478

[24] Muyan-Özçelik, P. (2017). A hands-on cross-platform mobile programming approach to teaching OOP concepts and design patterns. In Proceedings of the 1st International Workshop on Software Engineering Curricula for Millennials (pp. 33-39). IEEE Press. https://doi.org/10.1109/secm.2017.12

[25] Dodero, J.M., Mota, J.M., \& Ruiz-Rube, I. (2017). Bringing computational thinking to teachers' training: a workshop review. In Proceedings of the 5th International Conference on Technological Ecosystems for Enhancing Multiculturality (p. 4). ACM. https://doi. org/10.1145/3144826.3145352

[26] Nurbekova, Z., \& Aimicheva, G. (2018). Teaching Mobile Application Development: from the Idea to the Result. In 2018 3rd International Conference on Computer Science and Engineering (UBMK) (pp. 666-669). IEEE. https://doi.org/10.1109/ubmk.2018.8566488

[27] Luterbach, K. (2013). Promoting Computational Thinking by Developing Apps for Mobile Devices. In EdMedia+ Innovate Learning (pp. 1817-1822). Association for the Advancement of Computing in Education (AACE).

[28] Renumol, V., Jayaprakash, S., \& Janakiram, D. (2009). Classification of cognitive difficulties of students to learn computer programming. Indian Institute of Technology, India, 12. Retrieved from http://dos.iitm.ac.in/publications/LabPapers/techRep2009-01.pdf

[29] Rahman, F. (2018). Integrating Project-Based Learning in Mobile Development Course to Enhance Student Learning Experience. In Proceedings of the 19th Annual SIG Conference on Information Technology Education (pp. 1-6). International World Wide Web Conferences Steering Committee. https://doi.org/10.1145/3241815.3241851

[30] Kurkovsky, S. (2013). Mobile game development: improving student engagement and motivation in introductory computing courses. Computer Science Education, 23(2), 138157. https://doi.org/10.1080/08993408.2013.777236

[31] Rahman, F. (2018). Fostering Undergraduate Research through Mobile Development Course in PUIs. In Proceedings of the 19th Annual SIG Conference on Information Technology Education (pp. 56-57). International World Wide Web Conferences Steering Committee. https://doi.org/10.1145/3241815.3241845

[32] Alston, P. (2012). Teaching mobile web application development: challenges faced and lessons learned. In Proceedings of the 13th annual conference on Information technology education (pp. 239-244). ACM. https://doi.org/10.1145/2380552.2380620 
[33] Mobile Computing with App Inventor - CS Principles. Retrieved from https://courses.edx.org/courses/course-v1:TrinityX+T007x+1T2019/courseware/c68743e f825c4fcbb9fa23a6431e8ec5/6f0c1ed9b1de473e983268f1eeba7665/?child=last

[34] Faja, S. (2014). Evaluating Effectiveness of Pair Programming as a Teaching Tool in Programming Courses. Information Systems Education Journal, 12(6) pp 36-44. http://isedj.org/2014-12/ ISSN: 1545-679X.

[35] Powell, L. M., Wimmer, H. (2016). Evaluating Students' Perception of Group Work for Mobile Application Development Learning, Productivity, Enjoyment and Confidence in Quality. Information Systems Education Journal, 14(3) pp 85-95. http://isedj.org/2016-14/ ISSN: 1545-679X. (A preliminary version appears in The Proceedings of EDSIG 2015)

[36] Kannangara, Don and Fisher, Darrell. (2010). Programming Concepts, Teaching and Learning Styles and Cognitive Factors, in Chang, W-H. and Fisher, D. and Lin, C-Y. and Koul, R. (ed), Sixth International Conference on Science, Mathematics and Technology Education, Jan 19 2010, pp. 233-241. Hualien, Taiwan: 6th SMTE Organizing Committee

[37] Bruner, J.S (1960). The process of education. Cambridge, Mass: Harvard University Press

[38] Araujo, L. G. J., Bittencourt, R. A., \& Santos, D. (2018, February). An analysis of a media-based approach to teach programming to middle school students. In Proceedings of the 49th ACM Technical Symposium on Computer Science Education (pp. 1005-1010). ACM. https://doi.org/10.1145/3159450.3159526

[39] Hauser, U., \& Komm, D. (2018). Interdisciplinary Education in Mathematics and Informatics at Swiss High Schools. Bulletin of EATCS, 3(126).

[40] Nurbekova, Z. K., Mukhamediyeva, K. M., \& Assainova, A.Z. (2018). Educational Robotics Technologies In Kazakhstan And In The World: Comparative Analysis, Current State And Perspectives. Astra Salvensis, (11). (pp. 665-686)

[41] Sh. Shuinshina, Zh. Kopeyev, Y. Tuyakov, A. Mubarakov. (2019). Continuity in education: definition, essence and analysis of the problem. Ad alta: journal of interdisciplinary research. Volume 9, Issue 1. (pp. 271-278). ISSN 1804-7890. www.doi. org/10.33543/0901

[42] Zh. Kopeyev, A. Mubarakov, J. Kultan, G. Aimicheva, Y. Tuyakov. (2020). Using a Personalized Learning Style and Google Classroom Technology to Bridge the Knowledge Gap on Computer Science. International Journal of Emerging Technologies in Learning (iJET). eISSN 1863-0383, Volume 15, №2. https://doi.org/10.3991/ijet.v15 $\underline{\mathrm{i} 02.11602}$

\section{Authors}

Zhanat Nurbekova, Doctor of Pedagogy, Full Professor, Director of the Institute of digitalization of L.N. Gumilyov Eurasian National University, Satpayev str 2, 140000, Nur-Sultan, Kazakhstan, zhanat_n@mail.ru

Vadim Grinshkun, Doctor of Pedagogy, Full Professor, Head of Digital Education Department of Institute of Digital Education in Moscow City University, Moscow, Russian Federation, vadim@grinshkun.ru

Gaukhar Aimicheva, Senior Lecturer, Department of Computer science and Information Security, L.N. Gumilyov Eurasian National University, Satpayev str 2, 140000, Nur-Sultan, Kazakhstan, aimicheva@mail.ru 
Bakyt Nurbekov, Doctor of Pedagogy, Full Professor, Department of Higher Mathematics, L.N. Gumilyov Eurasian National University, Satpayev str 2, 140000, Nur-Sultan, Kazakhstan, b zh nur@mail.ru

Kalima Tuenbaeva, PhD in pedagogy, Library Director, Al-Farabi Kazakh National University, 71/27 al-Farabi Ave., 050000, Almaty, Kazakhstan, kalima_t@mail.ru

Article submitted 2019-11-13. Resubmitted 2020-01-27. Final acceptance 2020-01-27. Final version published as submitted by the authors. 